\title{
NOVO - FILTRO DE LINHA INTELIGENTE: O DESIGN EM UMA EQUIPE MULTIDISCIPLINAR
}

\author{
Aldrwin Hamad \\ Instituto Federal de Santa Catarina \\ aldrwin@gmail.com \\ Farleir Luís Minozzo \\ Instituto Federal de Santa Catarina \\ farleir.minozzo@ifsc.edu.br \\ Mateus Just Valli \\ Instituto Federal de Santa Catarina \\ mateusjustvalli@gmail.com
}

Resumo: Na atual conjuntura, em que as preocupações com gastos energéticos derivam de preocupações com o meio ambiente e do aumento do preço da energia, percebem-se inúmeros nichos de oportunidades para o desenvolvimento de soluções tecnológicas com a finalidade de amenizar esses gastos. Dentre esses nichos, existe no mercado, com mais força internacionalmente, uma linha de produtos chamados de "Filtro de linha inteligente". No âmbito nacional, além de poucas opções e problemas eletrônicos, esses produtos pecam em não evidenciar ao consumidor seu diferencial tecnológico, sendo esteticamente muito semelhantes à filtros de linha comuns. Diante de tal cenário, no âmbito do IFSC (Instituto Federal de Santa Catarina) e com auxílio do CNPQ (Conselho Nacional de Desenvolvimento Científico e Tecnológico), surge o projeto abordado nesse artigo, onde fica evidente os bons resultados gerados com a interdisciplinaridade acadêmica entre os cursos de Design de Produto e de Eletrônica, ambos do IFSC, aliados com a Industria. Para a elaboração da proposta contou-se com uma pesquisa de similares, levantamento de necessidades, definição dos requisitos do produto, geração de alternativas e, com base nos requisitos, a escolha da alternativa final. Como resultados, até o presente momento o projeto é ganhador da quinta edição do Prêmio Sinapse da Inovação, da Fundação CERTI, tem-se um pedido de patente de modelo de utilidade, fabricação de protótipos 3D e para o futuro pretendese iniciar a fabricação do molde do produto final e próximos passos para a comercialização.

Palavras-chave: Palavras Chave: Design de Produto, Equipamento eletrônico, Filtro de linha Inteligente. 


\begin{abstract}
In the current scenario, concerns about energy costs stem from worries about the environment and increased energy prices. There have been several opportunities to dilute these costs through the development of technological solutions. Among these, there is a line of products on the international market called "Smart Surge Protectors". However, in the national market these products are misrepresented due to their similar appearance to common line filters, resulting in consumers being blinded from their full potential. To correct this complication, the IFSC (Instituto Federal de Santa Catarina) and the CNPQ (National Council for Scientific and Technological Development) created the project discussed in this article. The project clearly displays successful results generated from the academic interdisciplinary knowledge provided by the Product Design courses and electronics from both the IFSC and the industry. The proposal was prepared through research of similar products, needs assessment, definition of product requirements, the generation of alternatives, and, based on the requirements, the choice of the final product. The project has already reached many commendable milestones, one of which was being awarded the fifth edition of the Synapse Award of Innovation claimed by the CERTI Foundation. Additionally, the project now has an application for a utility model patent and through $3 D$ prototyping and manufacturing, it intends to begin manufacturing the final product mould and finally branch into commercialization in the near future.
\end{abstract}

Keywords: Product Design, electronic equipment, Smart Surge Protectors

\title{
1. INTRODUÇÃO
}

O presente artigo é fruto de um projeto do CNPq, edital 17/2014 promovido pela SETEC/MEC, que visa a interdisciplinaridade acadêmica entre os cursos de Design de Produto e de Eletrônica do Instituto Federal de Santa Catarina campus Florianópolis (IFSC) aliados com a NOVO Indústria e Comércio de Transformadores, sediada em São José, no mesmo estado.

Numa crítica ao ensino de Design de produto no Brasil, Bonsiepe (2012) diz ser falho o método de ensino que exclui a indústria da universidade, já que essa atitude tira do aluno a oportunidade de realizar um verdadeiro projeto de produto que, segundo o autor, se divide em três fases: pesquisa, desenvolvimento tecnológico e aplicação industrial. Com esse projeto, já se cumpriram duas dessas três fases; e com o apoio da NOVO transformadores; do CNPQ e do Prêmio Sinapse da Inovação, da Fundação CERTI. Encaminha-se o início da terceira fase, com isso a equipe terá uma experiência plena de projeto, assim como a sociedade poderá usufruir-lhe, fazendo com que todo o investimento em pesquisa e desenvolvimento tenha, não só gerado frutos, mas servido como um agente social concreto.

"O processo de inovação se divide em três fases: pesquisa; desenvolvimento tecnológico; e aplicação industrial. Geralmente, existe uma descontinuidade entre as duas primeiras e a última, significando que a etapa de industrialização raramente é atingida. Com isso, não se consegue chegar a bom termo no processo de inovação. Nesse caso, os investimentos em 
pesquisa e desenvolvimento não produzem o esperado efeito multiplicador, deixando de gerar benefícios econômicos e sociais." (Bonsiepe, 2012, p.88)

A ideia do produto surgiu por volta de 2012, com os primeiros estudos sobre o assunto, de um estudante de eletrônica do IFSC. Em 2014, o projeto começou a ganhar mais força, quando foi contemplado com auxílio do edital 17 - 2014 do CNPq, que tinha como objetivo selecionar propostas para apoio financeiro a projetos que contribuam para o desenvolvimento científico, tecnológico e de inovação do País, por meio do estímulo à Pesquisa, Desenvolvimento e Inovação (PD\&I) e Extensão Tecnológica nas Instituições da Rede Federal de Educação Profissional, Científica e Tecnológica. Dentro do edital, o responsável pela inscrição, ciente da importância do Design para agregar valor ao produto, especificou que seria necessário um investimento voltado a essa demanda. Em meados de 2015, começaram a ser realizadas reuniões semanais com a equipe, que envolve profissionais e estudantes de eletrônica e de design.

As reuniões em grupo com profissionais, professores e estudantes de diferentes áreas - um professor da eletrônica, um professor do design, dois alunos do mestrado em mecatrônica, um aluno de graduação em design e dois alunos do curso técnico de eletrônica- fizeram com que o projeto ganhasse muito, pois tornaram as soluções encontradas muito mais fundamentadas e passíveis de fabricação, comercialização e utilização, devido ao engajamento e entendimento que foram contribuídos pelas diferentes áreas do conhecimento envolvidas.

A proposta trouxe aspectos de resistência, auxílio na fabricação, no processo de montagem, em possíveis adequações aos mercados internacional e estéticos. No decorrer do artigo serão explicados os principais pontos do processo, que teve como método base o modelo proposto por Back et al. (2008). No Processo de Desenvolvimento Integrado de Produtos (PRODIP), foram trabalhadas as seguintes etapas: 1) Projeto informacional; 2) Projeto conceitual; 3) Projeto preliminar e 4) Projeto detalhado.

O objetivo foi atender uma demanda direta do projeto, que atua em área estratégica de eletroeletrônicos. A demanda descreve a elaboração/concepção da carenagem, assim como a confecção de modelos tridimensionais.

\section{DESENVOLVIMENTO}

\subsection{Contexto de uso dos produtos}

As variações dos níveis de tensão para consumidores residenciais no Brasil são definidas pela regulamentação vigente (ANEEL, 2014). As concessionárias de energia recebem orientação para seguirem estes padrões, ou no caso de problemas receberão multas ou penalidades.

O estabilizador de tensão, também chamado de condicionador ou regulador de tensão, é utilizado para corrigir o valor de tensão para o consumidor. Sendo sua principal função a entrega da tensão regulada à carga, mesmo que ocorram variações de tensão na entrada, ou seja, na tensão fornecida pelas concessionárias. (PETRY, 2005).

No âmbito nacional, o estabilizador de tensão de baixa potência (Figura 1), surgiu no Brasil para regular a tensão de equipamentos utilizadores de válvulas. Com o surgimento dos computadores, os estabilizadores passaram a ser utilizados como um acessório, dito indispensável, dos Desktops ou computadores de mesa. Sendo 
utilizados como item de proteção, ou somente por possuir uma saída 110V (TORRES, 2014).

Seguindo esta linha de produtos os Filtros de Linha ou, popularmente chamando, "Réguas" (Figura 2) são utilizados com a intensão de proteger as cargas conectadas a ele, mas segundo estudos do Instituto Nacional de Metrologia, Qualidade e Tecnologia INMETRO (INMETRO, 2009), a qualidade desses produtos deixa a desejar em nosso país.

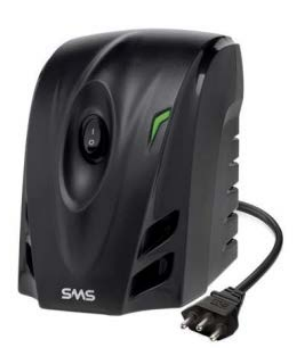

Figura 1 - Estabilizador de baixa potência.

Fonte: (SMS -

http://www.tecmundo.com.br/energia/10658-voce-sabiaque-usar-um-estabilizador-nao-serve-para-nada-.htm). Acessado em: 20/05/2016.

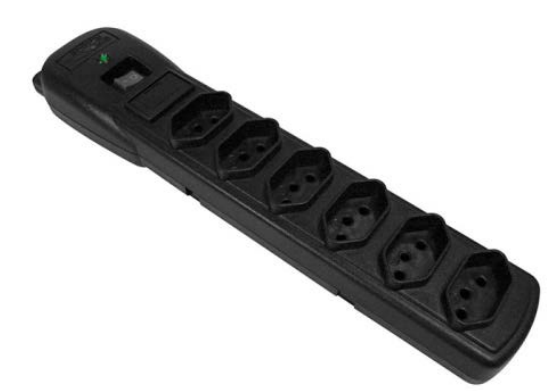

Figura 2 - Filtro de linha.

Fonte: (SMS - http://www.magazineluiza.com.br/filtro-delinha/informatica-e-acessorios/s/ia/iafl/). Acessado em: 20/05/2016

Segundo MINOZZO (2014), ambos os produtos citados são utilizados pelos Brasileiros, em sua maioria, com a intenção de proteção dos equipamentos eletroeletrônicos de informática e áudio vídeo.

Outra informação de importância norteadora para o projeto vem de dados do Instituto de Defesa do Consumidor, IDEC (2008). O estudo fala que o consumo de energia em uma residência pode aumentar em até $15 \%$ por estarem em modo de espera ou, o também conhecido anglicismo, Standby (termo este que será utilizado ao longo deste trabalho), sem operar. Já o INMTETRO (2014) afirma que cada televisor em modo Standby representa um aumento médio de dois reais por mês na conta residencial de energia.

Diante desse contexto viu-se a necessidade da criação de um produto, a fim não de substituir o estabilizador ou o filtro de linha, mas de criar uma nova linha de produto eletrônico, alinhado às novas demandas dos produtos eletrônicos modernos e do mercado. A criação de um produto que unisse as características mais relevantes do estabilizador e do filtro de linha, para atuar na proteção da carga com a característica adicional de economia de energia com a detecção inteligente de Standby em uma tomada principal, função esta que desliga equipamentos ligados em tomadas secundárias.

\subsection{Análise dos similares}

Com o intuito de reunir informações, comparar produtos, identificar soluções e ajudar no processo criativo de conceituação, aplicou-se o processo de análise de produtos similares. 


\begin{abstract}
"Antes de começar a projetar, é aconselhável analisar os produtos concorrentes, para obter respostas a questões como: Quais são as oportunidades para se projetar um produto mais competitivo? O que está funcionando bem? O que não funciona? Que mensagens se pretende passar? Que mensagens devem ser evitadas? Como o produto será percebido? Qual é a "tonalidade" que se quer dar ao produto? As respostas a essas questões podem ajudar o projetista a coletar elementos, formar opiniões e produzir insights para a criação do novo produto. " Philiphs, 2008.
\end{abstract}

Inicialmente as pesquisas da equipe foram voltadas a procura por produtos com similaridade tecnológica, caracterizados como "filtros de linha inteligentes". Dentro do Brasil foram poucos os similares encontrados, mas internacionalmente a pesquisa teve resultados relevantes dentro desse âmbito.

Porém dentre os "similares tecnológicos" houve pouca variação levando em conta as condições formais e estruturais (Figura 3, 4, 5 e 6). Assim fez-se necessária uma pesquisa mais abrangente que envolvesse todo o seguimento de filtros de linha.

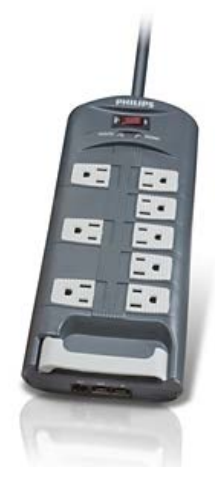

Figura 3 - Filtro de linha inteligente 1.

Fonte: (SMS - http://www.usa.philips.com/cp/SPP3222WA_17/home-office-8-outlets). Acessado em: 20/05/2016.

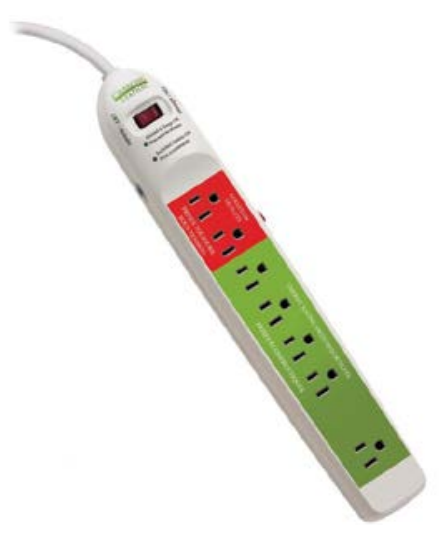

Figura 5 - Filtro de linha inteligente 3.

Fonte: (SMS - https://www.amazon.com/Bits-LimitedSPG-Charging-Station/dp/B003FLMX5G/188-69970031384244 ? $\mathrm{ie}=U T$ TF8 \& colid=2ITEV8KZZKV7S\& coliid=|3NZE4R | ZQW5NJ\&redirect=true\&ref_=wl_it_dp_v_S_img). Acessado em: 20/05/2016.

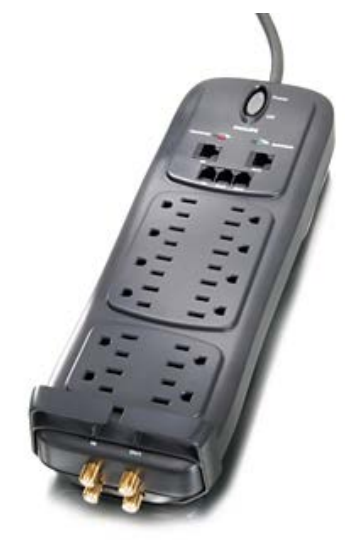

Figura 4- Filtro de linha inteligente 2. Fonte: (SMS - http://www.usa.philips.com/cp/SPP5145A_17/home-theater-surge-protector). Acessado em: 20/05/2016.

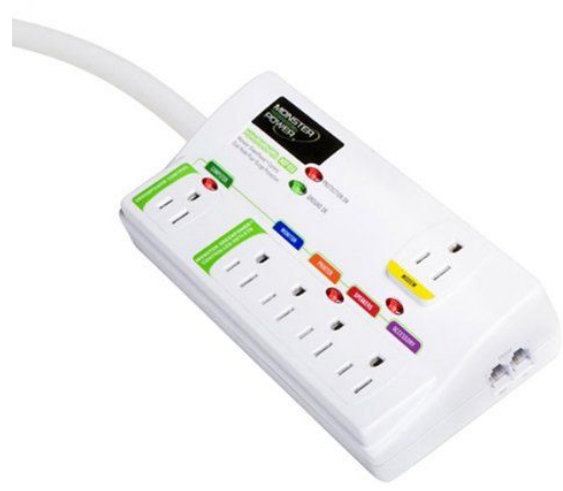

Figura 6 - Filtro de linha inteligente 4.

Fonte: (SMS - https://www.amazon.com/MonsterGreenPower-Digital-PowerCenter-

MDP/dp/B001LK6ZDE?ie=UTF8\&colid=2ITEV8KZZKV7S\&col iid=l185JXWCQT676Q\&redirect=true\&ref_=wl_it_dp_v_nS _img). Acessado em: 20/05/2016. 
Essa maior abrangência na pesquisa - que incluiu similares nacionais e internacionais, filtros de linha inteligentes ou não- trouxe resultados muito diversificados, com soluções formais interessantes e inovadoras. Valendo ressaltar os modelos (Figura 2), que foram inspiradores para o projeto por trazerem conceitos de modularidade, aproveitamento de espaço, formas de distribuição das tomadas para solucionar o problema dos diferentes tamanhos de fontes, botão "liga - desliga" para evitar choques no ato de retirar o filtro de linha da tomada, cabo de força destacável para que o consumidor escolha o que atenda melhor a sua necessidade, a separação da "tomada master" das demais para tornar o uso do aparelho mais intuitivo, além de fatores estéticos desses similares que visam ressaltar a tecnologia e a contemporaneidade de maneira limpa, exaltando a função do produto e a facilidade de seu uso.

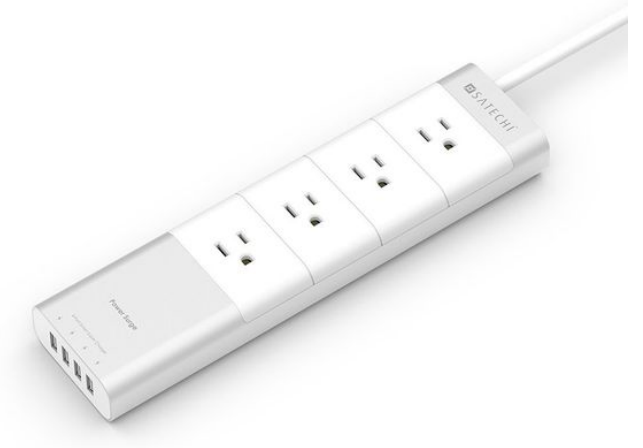

Figura 7 - Filtro de linha inteligente 1.

Fonte: (SMS -

https://macmagazine.com.br/2015/08/17/eu-quero-estanova-regua-da-satechi/). Acessado em: 20/05/2016.

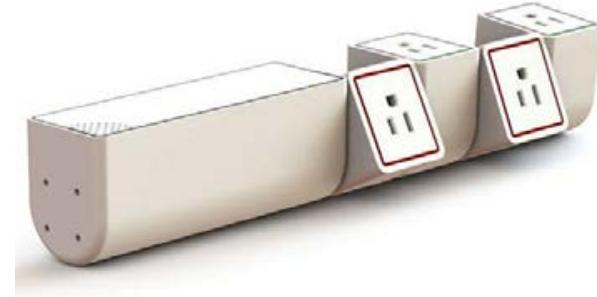

Figura 8 - Filtro de linha inteligente 2. Fonte: (SMS -

http://www.trendhunter.com/trends/modular-powerstrip) . Acessado em: 20/05/2016.

Com essa pesquisa pode-se mapear o perfil dos produtos existentes. Nacionalmente a categoria de filtros de linha inteligentes ainda não possui relevância (foram encontrados poucos similares), enquanto no exterior o mercado apresenta diversas opções. Tal situação evidencia uma categoria com oportunidade de crescimento, pois a importação e o uso no Brasil desses equipamentos torna-se muito dificultoso ao usuário, devido, entre outros fatores, a diferença dos padrões de saída das tomadas e normas de segurança especificas de cada país.

Realizada a análise de produtos similares observou-se potencialidades, problemas e características supérfluas. Com a análise em conjunto dos similares e da bibliografia, a equipe de design e de engenharia realizou um benchmark, traduzido em tabela, de alguns similares, afim de que todos tivessem um panorama e compreendessem os caminhos que o projeto iria tomar (Figura 9). 


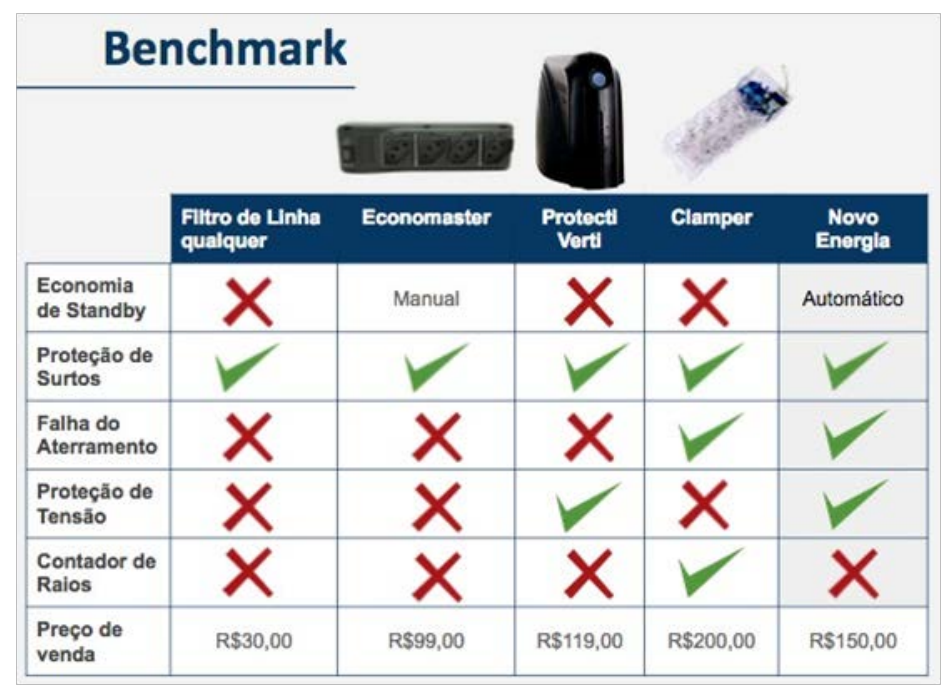

Figura 9 - Benchmark

Fonte: Elaborado pelo autor, com base na pesquisa realizada.

Por ser um produto relativamente inovador, não se encontrou produto similar ao ponto de realizar todas as funcionalidades propostas. Portanto, de maneira prática, criou-se um BenchMark baseado em quatro produtos: Filtro de linha comum, EconoMaster, Protecti Verti e Clamper e o, na época futuro, Novo Energia.

Estes foram analisados em três aspectos importantes para um filtro de linha inteligente: Possuir economia de standby, proteção de surto e proteção de tensão. Dentre os quatro, somente o EconoMaster possui economia no modo standby, porém o sistema funciona de forma manual, o que dificulta seu uso. Todos possuem proteção de surtos e somente o Protecti Verti possui proteção de tensão. Em consenso a equipe considerou o contador de raios, presente no similar Clamper, uma função desnecessária, já que o consumidor comum não julga necessária a obtenção da informação de quantos raios o produto protegeu seus aparelhos, podendo até gerar espanto. Estabelece-se assim uma oportunidade de mercado, na qual o cliente espera utilizar em casa um produto que traga como grande valor agregado uma solução inovadora para proteção e economia de energia de forma automática e em um único produto.

\subsection{DEFINIÇÃO DE REQUISITOS}

Como forma de verificar as similaridades, eliminar necessidades repetitivas e organizar de forma mais visual, para consultas rápidas, seguiu-se o recurso que segundo Back et al, 2008 é mais conveniente para esse agrupamento.

No quadro 1, tem-se a junção das principais necessidades apontadas pela equipe, baseando-se na análise da pesquisa bibliográfica e com usuários. Foram levados em consideração atributos como: Usabilidade, segurança, funcionalidade e estética. 


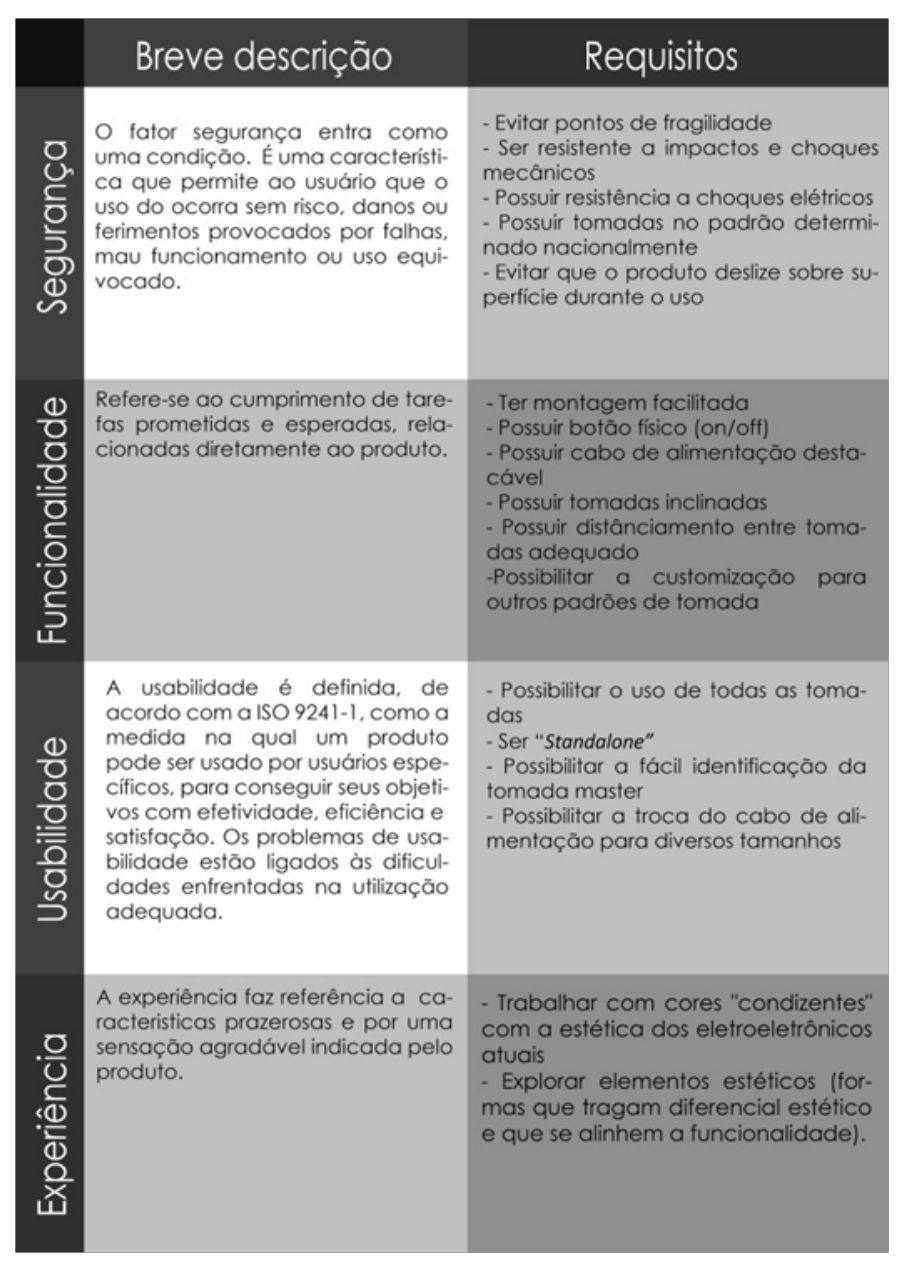

Fonte: Elaborado pelo autor, com base na pesquisa realizada.

\subsection{ETAPA CONCEITUAL}

Segundo Back et al. (2008) tendo posse das informações coletadas e dos requisitos estabelecidos, nesta etapa, procura-se desenvolver os primeiros esboços do produto. Com o intuito de estimular a criatividade e organizar os requisitos na concepção e no desenvolvimento das ideias, usou-se o método, inicialmente proposto em 1950, por Robert Crawford, da Universidade de Nebraska, conhecido como listagem de atributos, com o objetivo de melhorar algumas características nos objetos já existentes. Observou-se as principais qualidades dos similares afim de analisar as soluções e favorecer o surgimento de novas ideias (Back et al., 2008)

Seguindo este princípio, foram geradas alternativas em esboços manuais, que foram analisados com toda equipe para que a melhor ideia, levando em consideração a inovação e o cumprimento dos requisitos apresentados no quadro 1 , fosse selecionada e refinada em Software 3D. Antes do refinamento a equipe de design junto à de engenheiros eletrônicos, analisou os componentes da placa -para que o espaço interno do produto fosse bem aproveitado, reduzindo suas dimensões - e desenvolveu um esboço da mesma em software 3D. A fim de tornar a montagem do produto final mais simplificada, foi decidido que seriam utilizadas tomadas prontas, pois o processo de montagem delas é complicado, sujeito a erros e seu valor de compra é baixo. A mesma medida foi tomada com relação a saída do cabo de alimentação. Os componentes escolhidos também foram modelados, 
seguindo os datasheets dos fabricantes. Determinados esses limitantes dimensionais do projeto começou-se o modelamento da alternativa.

Requisito importante para o desenvolvimento do produto, foi o problema identificado gerado pela diferença nas dimensões das fontes dos eletroeletrônicos. Essa diferença, em filtro de linhas com posicionamento não angulado das tomadas causa, em alguns casos, a obstrução de tomadas paralelas como mostra na imagem.

A construção de um modelo virtual auxiliou na análise volumétrica (Figura 10), especificando as dimensões necessárias para acomodar os itens embarcados e prever as melhores opções de dimensionamento entre tomadas para acomodar as diferentes fontes.

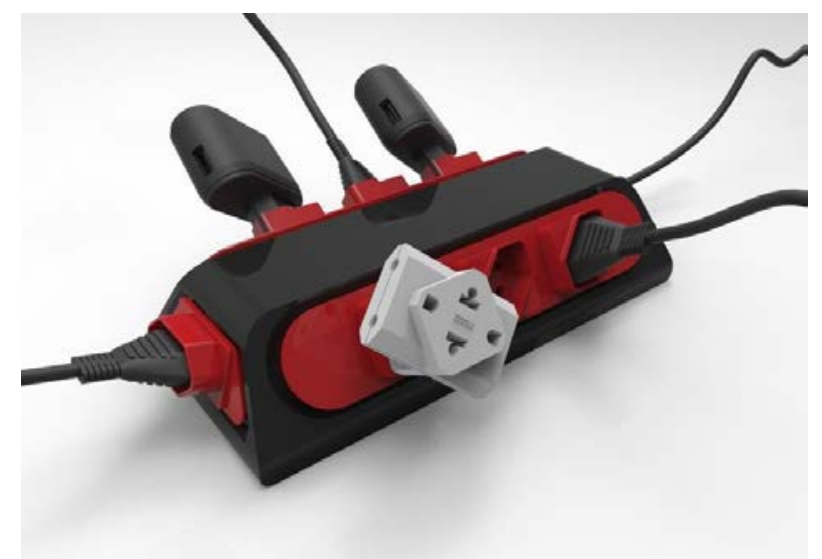

Figura 10 - Estudo de análise volumétrica.

Fonte: Elaborado pelo autor, com base na pesquisa realizada.

Ainda com relação às tomadas, o projeto foi idealizado visando futuras comercializações internacionais (Figura 11). Uma solução modular foi projetada para as partes laterais do produto, para que padrões diferentes de tomadas possam ser acoplados sobre a mesma base do produto, sem a necessidade de criação de um novo molde inteiro para isso.
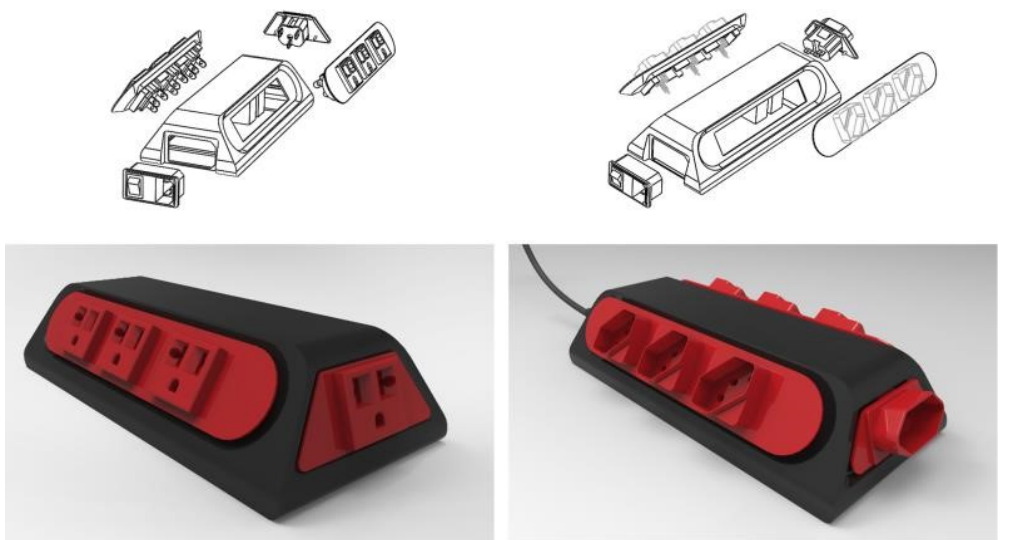

Figura 11 - Modularidade.

Fonte: Elaborado pelo autor, com base na pesquisa realizada.

O produto foi desenvolvido levando em consideração estudos de seus ângulos, tendo como objetivo a viabilidade produtiva, evitando potenciais problemas para retirada das peças do molde de injeção. Para tanto, foi utilizado um recurso 
importante do software 3D, nomeado como "Análise de Inclinação", que identifica ângulos negativos nas peças, com relação à faces escolhidas, com o uso de cores inclinação positiva (indicada pela cor verde), inclinação negativa (indicada pela cor vermelha) e faces que precisam de correção (mostradas em amarelo) ilustrando assim os melhores locais paraa realização de linhas de partição, vislumbrando a criação de um molde simples, sem o uso de gavetas, fácil extração da peça e gerando perdas quase nulas.

Para que que um produto contenha essas características e para que não haja falhas ou danos estruturais, segundo ASHBY (2010), o produto não deve ter angulação de 90 graus ou variações acentuadas, evitar rebaixos desnecessários e possuir espessura de parede constante (Figura 12).

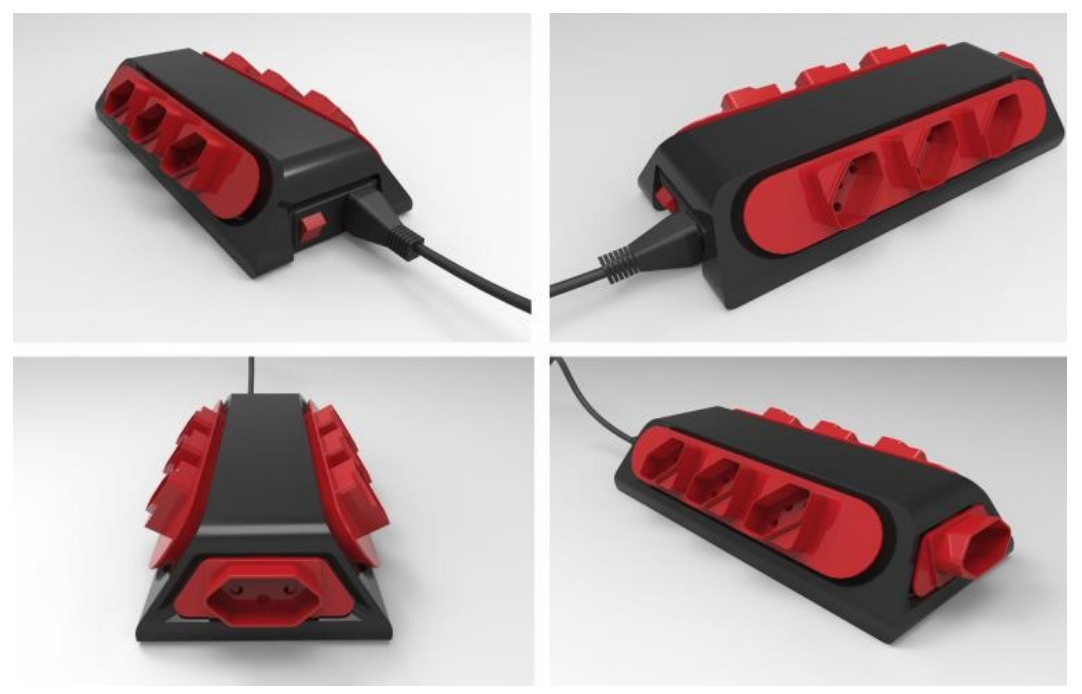

Figura 12 - Vistas.

Fonte: Elaborado pelo autor, com base na pesquisa realizada.

\subsection{PROJETO PRELIMINAR/DETALHADO}

Após a escolha da concepção final, começaram-se os estudos para a identificação dos processos produtivos mais adequados. Nesta etapa o objetivo é a materialização da proposta. Para isso foi realizado o detalhamento dos componentes e a descrição dos principais materiais empregados com o intuito de que a reprodução dos atributos e dos detalhes seja possível, mantendo-se assim a qualidade, os detalhes e aspectos do produto.

O produto possui cinco peças diferentes, duas delas em preto e as outras em vermelho, podendo haver mudança nas cores, mas mantendo-se o padrão das peças da estrutura base com cores iguais e as peças modulares em uma cor diferente. Sugere-se, assim, a fabricação de dois moldes, o que reforça a ideia da comercialização internacional.

Com relação ao material de composição do gabinete, foi indicado o uso de Acrilonitrila Butadieno Estireno - ABS, segundo ASHBY (2010) é uma abreviatura de "Acrylonitrile Butadiene Styrene", sendo um termo polímero obtido através da copolimerização dos monômeros Acrilonitrila, Butadieno e Estireno -, o mesmo vem sendo amplamente utilizado em eletroeletrônicos. O composto foi escolhido devido suas características estéticas, durabilidade e resistência. O uso do ABS garante ao 
produto uma duradoura superfície lisa e de alto brilho, evitando desbotamentos; possui resistência a impactos, a choques mecânicos e elétricos. Além disso, possibilita a obtenção de características específicas, por meio do balanceamento proporcional de sua composição - o monômero

Acrilonitrila confere ao ABS rigidez, resistência térmica e química, o Butadieno torna o produto mais dúctil e resistente a baixas temperaturas, o Estireno fornece uma superfície extremamente brilhosa, boa processabilidade e baixo custo. Sendo assim, pode se nivelar as quantidades de cada molécula para que o material tome características diferentes.

\section{CONCLUSÃO}

Este artigo relata os principais pontos trabalhados no desenvolvimento de um projeto com cunho empreendedor, o qual recebe auxílio de um edital do CNPQ que visa estimular a aproximação da universidade com a indústria, que demonstra sua solidez sendo finalista do programa Sinapse da Inovação e tendo em andamento um pedido de patente de modelo de utilidade.

A proposta trata-se do desenvolvimento de um "Filtro de Linha Inteligente", que visa reduzir o consumo de energia do modo Standby, a demanda surgiu de pesquisas sobre o desperdício gerado por esse modo.

Durante o processo informacional foram identificados produtos similares com maior força no mercado internacional. Dentro do Brasil foram encontrados alguns desses produtos estrangeiros e somente um produzido no país, mas de qualidade duvidosa.

No âmbito do design o projeto alcançou resultados interessantes, que possibilitaram a requisição de pedido de patente de modelo de utilidade, de maneira que cumpre os requisitos levantados e expostos durante o artigo, facilitando o uso, proporcionando ao produto maior competitividade, devido seu diferencial estético aliado à sua funcionalidade.

Para que se complete as três fases do projeto, segundo Bonsepie (2012), das quais só falta a última "Aplicação Industrial" para conseguir-se assim ter a experiência plena do ato de projetar. Há como próximas tarefas a realização de novos testes para a regulamentação do produto, obtenção de registros em órgãos regulamentadores, testes mais aprimorados para a viabilidade do molde, prospecção de fornecedores para o molde, aquisição e fabricação do mesmo. E para que o público tenha oportunidade de comprar o produto faz-se necessária a realização de tarefas que viabilizarão a comercialização, tais como a produção da embalagem, estratégias de venda, prospecção de locais de venda, entre outros pontos.

Como considerações sob a metodologia aplicada, a utilização do modelo proposto por Back et al. (2008) proporcionou que as tarefas fossem sistematizadas, ajudando na facilidade de integração dos conhecimentos, indispensável para a confecção da proposta. Embora o modelo apresente todas as fases do projeto, optouse por dar ênfase nas etapas de: Projeto informacional, Projeto conceitual e Projeto Preliminar Detalhado. Devido à dificuldade de exploração do modelo por completo, pois é voltado a empresas de manufatura, a escolha dessas etapas deu-se pela necessidade de abordar o assunto de maneira acadêmica e cientifica. 


\section{REFERÊNCIAS}

ASHBY, Michael; JOHNSON, Kara, 2010. Materiais e Design: Arte e Ciência da Seleção de Materiais no Design de Produto. 2.ed. Editora Campus, Rio de Janeiro, pp.87-89.

BACK, Nelson et al., 2008. Projeto Integrado de Produtos: planejamento, concepção e modelagem. Manole, São Paulo.

BONSIEPE, Gui. Design: como prática de projeto. Editora Edgard Blücher Ltda. São Paulo, 2012. 214p.

IDEC, 2008 - INSTITUTO BRASILEIRO DE DEFESA DO CONSUMIDOR. Energia desperdiçada. Disponível em: < http://www.idec.org.br/consultas/dicas-edireitos/cbnnovos-habitos-modo-stand-by-representa-15-da-conta-de-luz-dosbrasileiros >. Acesso em: 15 de fevereiro 2016.

INMETRO, 2014 - INSTITUTO NACIONAL DE METROLOGIA, QUALIDADE E TECNOLOGIA. Consumidor deve optar por produtos mais eficientes. Disponível em http://www.inmetro.gov.br/imprensa/releases/consumidor_produtos_mais_eficientes .pdf > . Acesso em: 05 de fevereiro 2016.

MINOZZO, Farleir Luís. Equipamento de Proteção Elétrica Bivolt com Medição de Tensão e Detecção de Consumo de Corrente para Eletrônicos. Florianópolis, setembro de 2014.

PETRY, Clóvis Antônio. Estabilizadores de Tensão Alternada para Alimentação de Cargas Não-Lineares: Estudo de variações topológicas e métodos de controle. Tese de Doutorado. Março de 2005.

PHILLIPS, Peter L. Briefing: a gestão do projeto de design. Blucher, 2008.

TORRES, Gabriel. Vídeo sobre Filtros de Linha. Publicado em 14 de Agosto 2014. Disponível em: < http://www.clubedohardware.com.br/artigos/Video-tudo-oquevoceprecisa-saber-sobre-filtros-de-linha/2995 > . Acesso em: 13 de fev. 2016. 